\title{
CAREER: A Study of How Engineering Students Approach Innovation
}

\section{Dr. Senay Purzer, Purdue University, West Lafayette}

Şenay Purzer an Assistant Professor in the School of Engineering Education at Purdue University. In 2011, she received a NSF CAREER award, which examines how engineering students approach innovation. She is also a NAE/CASEE New Faculty Fellow. Purzer conducts research on aspects of design education such as innovation and information literacy.

\section{Mr. Nicholas D. Fila, Purdue University, West Lafayette}

Nicholas D. Fila is a Ph.D. student in the School of Engineering Education at Purdue University, West Lafayette. His research interests include how engineering students approach, learn, and internalize design, especially in teams. He has co-authored a book chapter on teamwork and innovation, and has authored conference and journal papers on design, innovation, collaboration, and engineering laboratories.

\section{Mr. Paul David Mathis, Purdue University}

Paul Mathis is a PhD student in the school of Engineering Education and a council member for ASEE student chapter at Purdue University. He has a bachelors degree in Physical Science and a Masters in Education Curriculum. His areas of interest are design, innovation, creativity and improving skills of future engineers.pmathis@ purdue.edu. 


\title{
CAREER: A Study of How Engineering Students Approach Innovation
}

\begin{abstract}
Despite the crucial link between engineering and innovation, research on engineering education in innovation is limited. While prior studies highlight some of the individual characteristics important for creativity, characteristics of innovators and entrepreneurs, and the critical role of organizations in supporting innovation, very little is known about how engineering students approach innovation and ways to measure these processes and their outcomes. The research component of this CAREER project aims to characterize how engineering students view and approach innovation. Aspects of the research that are accomplished so far include: 1) a multi-phase protocol that includes interviews, process mapping tasks, and think-aloud protocols, 2) a content analysis to determine typical innovation and discovery behaviors used in innovation in technical areas, and 3) a meta-synthesis of assessment methods used in engineering entrepreneurship. Based on the findings from these studies, we made recommendations that inform activities associated with the educational plan including classroom activities and assessment tools.
\end{abstract}

\section{Introduction}

While innovativeness is a necessary skill for engineers, research on how engineering students approach innovation and ways to measure these processes and their outcomes is limited. In contrast with the need for and importance of innovation, recent studies show that engineering education does not always nurture innovative thinking. In a recent study, Genco and her colleagues $(2010)^{1}$ found that undergraduate seniors in engineering were less innovative in their design solutions than their first-year engineering counterparts. Another study, conducted by the Center for the Advancement of Scholarship on Engineering Education (CASEE), also compared first-year and engineering students and seniors. In their study, seniors perceived creativity to be less important for engineering than first-year engineering students ${ }^{2}$.

One way higher education institutions have addressed these calls for the development of an innovation workforce and concerns about graduates' abilities to innovate has been through the development of special programs. Today, many higher education institutions offer minors and certificate programs that allow students to learn about innovation. Some of these programs are university wide (e.g., Purdue) and others are developed within the colleges of engineering (e.g., University of Maine). While emerging studies on the effectiveness of these programs are promising (e.g., Duval, Reed-Rhoads, Haghighi, 2010 ${ }^{3}$ ), often these evaluations focus on the assessment of psychological factors or student perceptions rather than the assessment of knowledge, skills, and abilities.

Another way engineering education programs support the development of an innovative workforce is by diversifying the student population. It is argued that innovation is propelled when diverse people work together. While some research on gender and cultural differences in design education point to possible differences (e.g., Kilgore, Atman, Yasuhara, Barker, \& Morozov, 20074 ; Cady and Valentine $1999^{5}$ ), we do not know if and how these approaches are linked to innovativeness of design outcomes. More research is needed to inform how engineering students 
approach innovation, the skills and behaviors students develop during their education, and whether there is sufficient evidence for gender and cultural differences that are claimed to be critical for innovation.

\section{Project Goal and Objectives}

This NSF CAREER project, currently in its second year, is designed to study the extent to which engineering students possess or demonstrate the skills held by innovators. An examination of educational background, gender, and cultural differences will help develop a framework for diversity and innovation and create research-based learning opportunities for students. At the end of this project, four research and three educational goals will be accomplished.

\section{Research Goals}

- Identify students' approaches to innovation and the agents that support or hinder their abilities to innovate.

- Study the personal backgrounds, skills, and academic characteristics of engineering students in relation to how they approach innovation.

- Examine if and how engineering students who pursue an innovation-focused education program differ from others.

- Identify if and how gender and cultural differences shape innovative behavior and solutions.

\section{Educational Goals}

- Improve teaching practices through curriculum shown to be effective at stimulating creativity and supporting innovation skill development.

- Design, validate, and disseminate tools that support formative assessment and measure changes in learning.

- Develop and present faculty and K-12 teacher workshops that link research findings and classroom practice.

\section{Key Findings}

\section{Study \#1: Engineering Students' Conflict between Technical and Creative Identity}

While much research has focused on student creativity and innovation skills, understanding students' perceptions of innovation and the learning experiences that shape these perceptions can help explain the supporters and hindrances influencing their innovativeness. We conducted a multiple-case study involving seniors in various engineering disciplines. These students participated in think-aloud protocols and semi-structured interviews.

We found that students' engineering identity as a technical problem solver contradicted with their creative identity. This manifested in their perceptions of themselves as being technical problem solvers and non-creative. They avoided creative solutions that are not immediately feasible due to fear of failure. They also tended to outsource creative tasks to those who are not engineers, considering engineering to be a technical rather than a creative field. 


\section{Study \#2: A Content Analysis of Case Studies Published in Bestseller Innovation Books}

In an earlier study involving leaders in innovation companies, Dyer and his colleagues ${ }^{6}$ identified five discovery skill that they call The Innovator's DNA: observation, questioning, experimenting, networking, and association. Their study, however, does not report the relationship between these skills and their importance at different stages of the innovation process. We reviewed more than 100 bestselling books on innovation to identify those that included a large number of case studies on technological innovations with sufficient detail. Fifty-four cases in three books (The Innovator's DNA, The Ten Faces of Innovation, and The Medici Effect) were analyzed for the five skills identified Dyer et al (2011).

Our analysis showed that successful innovators had a distinct pattern of behavior for discovery. The most common path was observation to questioning to experimenting. The majority of innovation cases begin with observation, such as the observation of the surroundings or user behavior, and ended with experimenting. Among the five skills, observation and questioning were the most critical and central to innovation (See Table 1).

Table 1. Essential Discovery Skills

\begin{tabular}{ll}
\hline Discovery Skill & Place in the Innovation Process \\
\hline Observation & Most frequent entry to the innovation process \\
Questioning & Central to innovation \\
Experimenting & Most frequent exit from the innovation process \\
\hline
\end{tabular}

\section{Study \#3: Meta-synthesis of Assessments in Engineering Entrepreneurship Education}

Quality assessment, when conducted properly, can aid student learning and improve educational programs. In a meta-synthesis study, we evaluated the current state of assessment in engineering education with a specific focus on entrepreneurship. Our analysis resulted in more than forty assessment instruments on entrepreneurship in engineering.

The majority of the assessment instruments we identified were used to evaluate project deliverables; although these instruments often lacked details about specific competencies that are critical for formative feedback. Self-report surveys were also popular; however, often they were used with limited evidence on validity. We describe a five-stage process to improve assessment in the context of engineering entrepreneurship.

\section{Recommendations Related to Educational Goals}

In light of findings from the three studies summarized above, we identified a set of recommendations for engineering education to support student creativity and innovation.

(1) Classroom assessment practices should be re-evaluated to identify grading policies and implicit messages that hinder creative behavior. Efforts should be made to reinforce creativity as a critical aspect of engineering identity. 
(2) Engineering education should emphasize three discovery behaviors: observation, questioning, and experimenting. These skills and importance of these skills should be explicitly taught not only to support students' ability to solve technical problems but also to support their ability to innovate.

(3) A system of evidence-based assessment should be developed to evaluate student learning. These include competency-based rubrics that help document student improvement in specific areas of innovation, as well as tests and questionnaires that have gone through rigorous psychometric evaluation.

\section{Expected Significance}

Engineering drives innovation through the development of new processes and technologies. Hence, fostering innovation is an important goal of engineering education. Fostering innovation is also a national goal, as addressed by President Obama's Strategy for American Innovation, which acknowledges innovation as the heart of U.S. economic growth (National Economic Council, Council of Economic Affairs, \& Office of Science and Technology Policy, $\left.2011^{7}\right)$.

As we conclude the second year of this five-year project, we used both synthesis and empirical studies to examine engineering students' views of innovation and abilities to innovate as well as educators' ability to teach and assess the development of these abilities. Our research so far has identified a critical problem. Innovativeness, though an essential attribute needed for engineers, is not one that resonates with the engineering identity of soon-to-be graduates of engineering.

Our future efforts will focus on disseminating our results and developing strategies that guide efforts necessary to realize the nation's vision for developing an innovative engineering workforce. Our future research will also focus on identifying the level with which engineering students exhibit skills found in innovators as well as comparisons between groups of first-year and senior-level engineering students. Gender and cultural differences will also be analyzed.

\section{Acknowledgment}

This material is based upon work supported by the National Science Foundation CAREER grant in Engineering Education under Grant No. 1150874. Any opinions, findings and conclusions or recommendations expressed in this material are those of the authors and do not necessarily reflect the views of the National Science Foundation. 


\section{References}

${ }^{1}$ Genco, N., Holtta-Otto, K., \& Seepersad, C. C. (2010). An experimental investigation of the innovation capabilities of engineering students. Proceedings of the 2010 American Society of Engineering Education Annual Conference \& Exposition.

${ }^{2}$ Atman, C. J., Sheppard, S. D., Turns, J., Adams, R. S., Fleming, L. N., Stevens, R., et al. (2010). Enabling engineering student success: The final report for the Center for the Advancement of Engineering Education. San Rafael, CA: Morgan \& Claypool Publishers.

${ }^{3}$ Duval-Couetil, N., Reed-Rhoads, T., \& Haghighi, S. (2011). Investigating the impact of entrepreneurship education on engineering students. Proceedings of Open 2011: NCIIA 15 th Annual Conference.

${ }^{4}$ Kilgore, D., Atman, C.J., Yasuhara, K., Barker, T.J., \& Morozov, A.E. (2007). Considering Context: A Study of First-Year Engineering Students. Journal of Engineering Education, 96(4), 321-334.

${ }^{5}$ Cady, S. H. \& Valentine, J. (1999). Team Innovation and Perceptions of Consideration: What Difference Does Diversity Make? Small Group Research, 30, 730-750.

${ }^{6}$ Dyer, J., Gregersen, H., \& Christensen, C. M. (2011). The innovator's DNA: Mastering the five skills of disruptive innovators. Harvard Business Press.

${ }^{7}$ National Economic Council, Council of Economic Affairs, \& Office of Science and Technology Policy. (2011). A strategy for American innovation: Securing our economic growth and prosperity. Washington, DC: Authors. 